\section{Wizard of domes}

\author{
David E.H. Jones
}

Inventions: The Patented Works of

R. Buckminster Fuller.

By R. Buckminster Fuller.

St Martin's Press: 1983. Pp.316.

$1.75 \mathrm{~kg}, \$ 40$.

THE most dramatic spiritual conversion leaves the same person underneath. $\mathbf{R}$. Buckminster Fuller, whose 28 patents are collected in this heavy tome, is a case in point. In 1927, at the age of 32 , seeing himself as a total failure and contemplating suicide, he made instead a profound resolution to commit "ego-cide". Abandoning concern for himself, he dedicated his life to the problems of all humanity, to find out what one man could do to solve them. As the subject of this personal experiment, he nicknamed himself "Guinea Pig B" (B for Buckminster). What shines through this work is that Guinea Pig B was an outrageous egotist.

Fuller is an appalling writer. $\mathrm{He}$ is capable of explaining his commitment to a "never-again-for-self-use employment of my omni-experience-gained knowledge", And since this book consists of his patent applications - a forbidding literary form even in skilled hands - and his adulatory comments upon them, reading it is like trying to bicycle through sand. FurtherADVERTISEMENT

\section{PRACTICAL MACROMOLECULAR} ORGANIC CHEMISTRY

by Dletrich Braun. Harald Cherdron and Werner Rern translated by Konnoth J. Irvin A volume in the MMI Press Polymer

Monograph series

April 1984 3-7186-0059-5

339 pp.

\section{NMR SPECTROSCOPY}

edited by Eberhard Breitmeier and

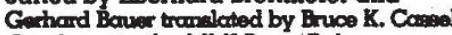
$A$ volume in the MMI Press Polymer

Monograph series

April 1984 3-7186-0027-7

$431 \mathrm{pp}$

\section{CHEMISTRY REVIEWS}

Soviet Scientific Reviews Section B

odited by M.E. Vol'pin

Vol.5: April 1984 3-7186-0137-0

approx. 305 pp.

Vol.6: Summer 1984 3-7186-0139-?

3-7186-0139-7

SERIES NOW AVAILABLE ON

SUBSCRIPTION FOR \$140.00 PER

VOLUME

\section{IONIC HYDROGENATION AND}

\section{RELATED REACTIONS}

\section{edited by D.N. Kurscmov,}

\section{Z.N. Parnes, M.I. Ralinktin and}

N.M. Loim translated by Loo Wiene

$A$ volume in the Chemistry Reviews

Supplement Series, Soviet Scientific

Reviews, Section B

Autumn 1984 3-7186-0145-1

approx. 230 pp.

\title{
Waves, particles and
} paradoxes

Some of his inventions, such as his "Dymaxion car" of 1933 , now seem very shallow exercises; and his thinking is often woolly. Thus he repeatedly claims that some of his structures are far stronger than stress-analysis would predict, and that a mysterious "synergy", unpredicted by the properties of their components, is at work within them. He is also given to sloppy philosophy and sixties-style eco-nut moralizing. This aspect of his thinking cannot command respect.

But Fuller was also one of the great originals of American engineering. He could imagine in three dimensions, and his most interesting patents are those concerned with three-dimensional structures: 11 geodesic domes, one spacefilling girder lattice, and a world map. They were devised between 1944 and 1975; his major contribution to engineering only began to crystallize 30 years after he began his career as Guinea Pig B. Geodesic construction was not new when he came to it (Barnes Wallis had used it in the Wellington bomber). But his development of it into a practical architecture for big domes shows real engineering genius. And tensegrity construction is Fuller's alone, and it is wonderful. It produces a rigid stressed lattice with no continuous compression frame; Patent 15, which introduces this seemingly impossible form of construction, is to my mind the most compelling in the book. It is worth persevering with the convoluted description to gain an understanding of how such an audacious structure can work. The idea is a splendid vindication of Fuller's resolve of 1927: it exemplifies perfectly what one independent and original mind can contribute to the world.

And yet for engineers, tensegrity construction is still just a clever idea. Even the geodesic dome remains a specialized and rather self-conscious architectural form. And none of Fuller's other inventions has been seriously taken up, or has contributed to the idiom of modern engineering. Not much of Fuller's thinking has changed the world we live in; in a sense, his most important invention was himself. For over half a century, Guinea Pig B pursued his individual path of engineering creativity quite outside the American scientific and technological establishment. But this his last book, beginning with his relentlessly congratulatory introduction and ending with his $\mathbf{4 3}$ honorary degrees (each with its fulsome dedication) compels the thought that, so far at least, the main global effect of his bold and courageous career of self-effacement has been to gain renown for its author.

David E.H. Jones is a guest staff member of the Physical Chemistry Department, University of Newcastle upon Tyne, and a science consultant to industry and the media. He is author of The Inventions of Daedalus: A Compendium of Plausible Schemes, published by $W$. H. Freeman in 1982.

\section{John Stachel}

The Tiger and the Shark: Empirical

Roots of Wave-Particle Dualism.

By Bruce R. Wheaton.

Cambridge University Press: 1983.

Pp.355. £22.50, \$39.50.

$\mathrm{X}$-RAYS have become a household word through their medical uses. Yet their discovery by Wilhelm Röntgen at the end of 1895 launched a tremendous publicity wave for the phenomenon, a then exotic and glamorous topic. Röntgen must have been one of the earliest physicists to pen the now familiar complaints: "I could not recognize my own work in the reports any more . . . . Gradually I became accustomed to the uproar, but the storm cost time. For exactly four weeks I have been unable to do a single experiment!'”. The glamour gradually wore off, but puzzlement as to the nature of the new radiation did not.

The object of Bruce Wheaton's book is

to clarify the developing understanding of $\mathrm{X}$-rays and related phenomena early in the twentieth century. But it is the physicists' growing awareness that [classical] electromechanical explanations of the radiation would not work in principle that forms the real subject of this book [p.2].

The method by which he seeks to realize this goal is a detailed reconstruction of the course of experimental and theoretical studies of $\mathrm{X}$ - and $\gamma$-rays, and some related topics in optics and atomic structure, from the discovery of X-rays until the presentation of de Broglie's thesis in 1924, summarizing his work on the wave-particle duality for ordinary matter. One of the most striking featues of the book is the meticulous care with which experimental investigations and the theoretical controversies which they stimulated are reconstructed. The rigour with which Wheaton strives to avoid introduction of anachronistic elements into his discussion (he apologizes profusely at one point when he feels such an omission would be too confusing), helps to convey to the reader a real feeling for the "state of the art" at various periods, including the confusions and wrong turns, as well as a sense of the undoubted if irregular long-run progress made in the understanding of these new and puzzling phenomena. Here we are far indeed from sanitized text-book versions of the history of great scientific discoveries. This feature of the book should make it of interest to many readers with a general interest in the history of science, over and above its obvious appeal to specialists in the history of quantum theory.

Wheaton details the early controversies over whether X-rays were particulate or electromagnetic in nature; and, if electro- 